\title{
Preface for the Special Volume on Exploration and Environmental Considerations of Deep Seabed Mineral Resources
}

\author{
Kiseong Hyeong ${ }^{1}$, Se-Jong $\mathrm{Ju}^{1}$, David Billett ${ }^{2}$, and Ashley Rowden ${ }^{3}$ \\ Guest editors of Special Issue \\ ${ }^{1}$ Deep-sea and Seabed Mineral Resources Research Center, KIOST, Busan 49111, Korea \\ ${ }^{2}$ Deep Seas Environmental Solutions Ltd., Hampshire SO40 7AP, UK \\ ${ }^{3}$ National Institute of Water and Atmospheric Research, Wellington 6021, New Zealand
}

Increasing demand for metals and the depletion of landbased resources have aroused growing interest in marine mineral resources over the past decade. Seabed mineral resources targeted for commercial exploitation are seafloor massive sulfides (SMS), Co-rich ferromanganese crusts and polymetallic nodules, which include copper, nickel, zinc, cobalt, iron, manganese and rare earth elements as main metals. At present, commercial-scale seabed mining operations are only active for resources on continental shelf (e.g. diamonds, iron sands, and phosphorites). However, there have been growing number of tenures for exploration and exploitation for deep $(>200 \mathrm{~m})$ seabed mineral resources in the exclusive economic zone (EEZ) of coastal States and the Area, the seabed beyond national jurisdiction.

To date, exploitation licenses have been issued for two SMS deposits in the Bismarck Sea (Solwara 1) and Red Sea (Atlantis II). On-site test mining was also carried out for the first time for SMS in Japanese water (Okinawa Trough) in 2017. Commercial exploitation of SMS is expected to begin in several years. In contrast to movements for the seafloor massive sulfide deposits in the EEZ, other two seabed mineral resources, nodules and crusts, as well as seafloor massive sulfides in the Area are far from the stage of commercial operation. As of today, however, a total of 29 exploration licenses have been awarded for the exploration of these mineral deposits by the International Seabed Authority (ISA), an autonomous international organization that regulates and controls activities relating to seabed mineral resources in the

*E-mail: kshyeong@kiost.ac.kr, sjju@kiost.ac.kr, david.billett@deepseasolutions.co.uk, ashley.rowden@niwa.co.nz area beyond the limits of national jurisdiction. Among them, 21 contracts have been granted in the last 7 years, which clearly points to growing interest in commercial mining of these mineral deposits in recent years. In addition, the ISA is in the process of formulating "regulations on exploitation of mineral resources in the Area" (ISA 2012). Completion of the exploitation code is expected to provide additional momentum to expedite the commercial-scale mining of mineral resources in the Area.

With the imminence of a regime change from exploration to exploitation in deep-sea mining there are growing concerns on the environmental impacts from the projected mining activities in the future. It is widely accepted view, given the nature and scale of mining operations, that negative impacts on biodiversity are inevitable (Miller et al. 2018) and are likely to be irreversible (Van Dover et al. 2017). The MIDAS (Managing Impacts of Deep-seA resource exploitation) project investigated the potential environmental issues and scales of impacts, based on a predicted mining scenario, related to exploitation of polymetallic nodules and seafloor massive sulfides (MIDAS 2016). However, environmental impacts from seabed mining cannot be predicted with certainty at this stage as commercial scale seabed mining is unprecedented. MIDAS (2016) addressed most of critical environmental issues and provided recommendations for future study to better understand the potential impacts of seabed mining on deep-sea ecosystems.

This special edition includes 10 articles that are dedicated to the broad range of topics on seabed mineral resources. Special emphasis is given on environmental baseline data 
(biotic and abiotic properties) in the nodule field of the ClarionClipperton Fracture Zone. These data are biodiversity and abundance of macro-, meio- and micro-fauna and bioturbation rates and rock magnetic properties of deep-sea sediments, all of which are essential for the assessment of environmental impacts from the exploration and exploitation of polymetallic nodules. An article also touches on the legal tools and mechanisms adapted in the exploitation regulations by the ISA for the protection of the marine environment. Other topics include petrogenetic and magnetic modeling of SMS deposits, sinking particle flux in a crust distribution area and resources assessment using acoustic backscatter intensity data in the polymetallic nodule field. This edition covers only small number of topics among wide range of issues related to deep seabed mining. We sincerely hope that this special edition may foster further scientific researches and provide an opportunity to share with scientific communities the acquired environmental data and research tools in the seabed mining area. Lastly, we would like to thank OSJ for generously accepting the issue of this special edition as well as the Ministry of Oceans and Fisheries (PM60591, 60322) and Korea Institute of Ocean Science and Technology (PE99616) for the support for this special edition. Special thanks to the reviewers for their valuable comments and suggestions on the manuscripts submitted.

Note. ISA (2012) Workplan for the formulation of regulations for the exploitation of polymetallic nodules in the Area. ISAB/18/C/4, International Seabed Authority, Kingston

MIDAS (2016) Managing impacts of deep-sea resource exploitation. https://www.eu-midas.net/ Accessed 4 Jun 2018

Miller KA, Thompson KF, Johnston P, Santillo D (2018) An overview of seabed mining including the current state of development, environmental impacts, and knowledge gaps. Front Mar Sci 4:418. doi:10.3389/fmars.2017.00418

Van Dover CL, Ardron JA, Escobar E, Gianni M, Gjerde KM, Jaeckel A, Jones DOB, Levin LA, Niner HJ, Pendleton L, Smith CR, Thiele T, Turner PJ, Watling L, Weaver PPE (2017) Biodiversity loss from deep-sea mining. Nat Geosci 10:464-465. doi:10.1038/ngeo2983 